\title{
Front Matter: Volume 8335
}

, "Front Matter: Volume 8335," Proc. SPIE 8335, 2012 International Workshop on Image Processing and Optical Engineering, 833501 (15 November 2011); doi: $10.1117 / 12.920031$

SDIE Event: 2012 International Workshop on Image Processing and Optical Engineering, 2012, Harbin, China 


\section{PROCEEDINGS OF SPIE}

\section{International Workshop on Image Processing and Optical Engineering}

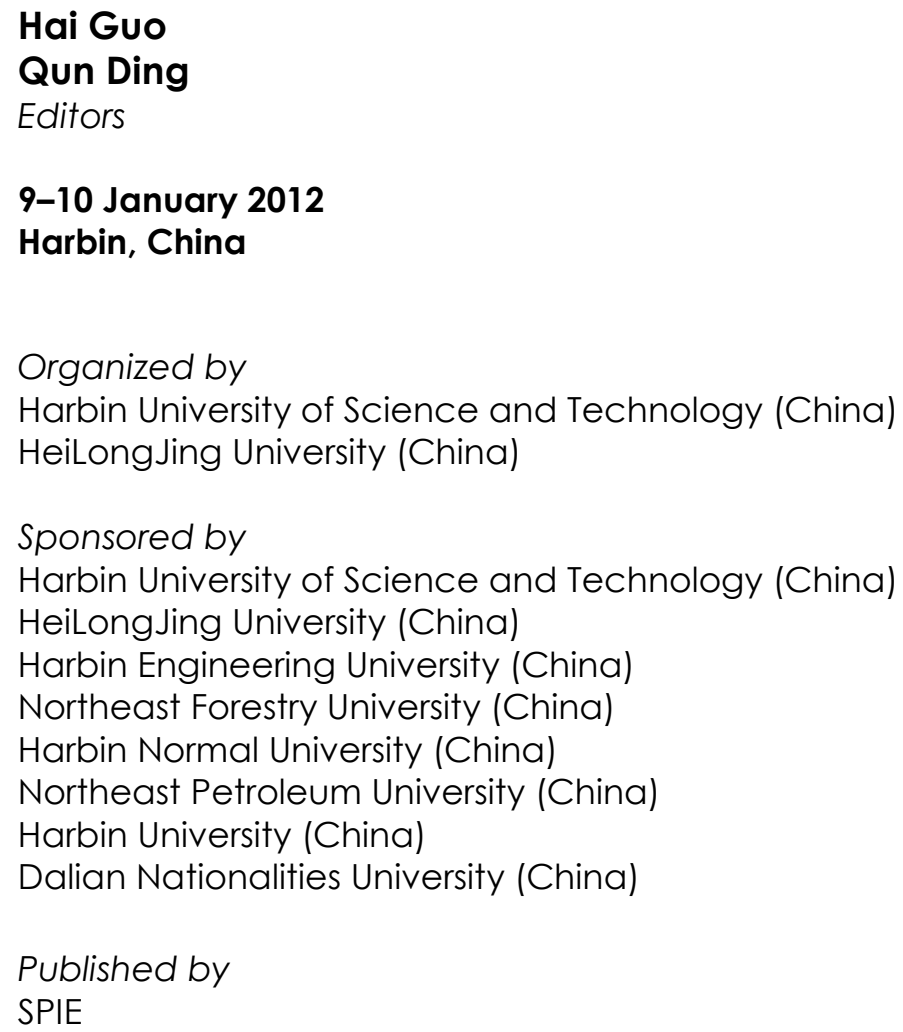

Hai Guo

Qun Ding

Editors

9-10 January 2012

Harbin, China

Organized by

Harbin University of Science and Technology (China)

HeiLongJing University (China)

Sponsored by

Harbin University of Science and Technology (China)

HeiLong Jing University (China)

Harbin Engineering University (China)

Northeast Forestry University (China)

Harbin Normal University (China)

Northeast Petroleum University (China)

Harbin University (China)

Dalian Nationalities University (China)

Published by

SPIE

Volume $\mathbf{8 3 3 5}$ 
The papers included in this volume were part of the technical conference cited on the cover and title page. Papers were selected and subject to review by the editors and conference program committee. Some conference presentations may not be available for publication. The papers published in these proceedings reflect the work and thoughts of the authors and are published herein as submitted. The publisher is not responsible for the validity of the information or for any outcomes resulting from reliance thereon.

Please use the following format to cite material from this book:

Author(s), "Title of Paper," in 2012 International Workshop on Image Processing and Optical Engineering, edited by Hai Guo, Qun Ding, Proceedings of SPIE Vol. 8335 (SPIE, Bellingham, WA, 2011) Article CID Number.

ISSN 0277-786X

ISBN 9780819489920

Published by

SPIE

P.O. Box 10, Bellingham, Washington 98227-0010 USA

Telephone +1 3606763290 (Pacific Time) · Fax +1 3606471445

SPIE.org

Copyright (C) 2011, Society of Photo-Optical Instrumentation Engineers

Copying of material in this book for internal or personal use, or for the internal or personal use of specific clients, beyond the fair use provisions granted by the U.S. Copyright Law is authorized by SPIE subject to payment of copying fees. The Transactional Reporting Service base fee for this volume is $\$ 18.00$ per article (or portion thereof), which should be paid directly to the Copyright Clearance Center (CCC), 222 Rosewood Drive, Danvers, MA 01923. Payment may also be made electronically through CCC Online at copyright.com. Other copying for republication, resale, advertising or promotion, or any form of systematic or multiple reproduction of any material in this book is prohibited except with permission in writing from the publisher. The CCC fee code is 0277-786X/11/ \$18.00.

Printed in the United States of America.

Publication of record for individual papers is online in the SPIE Digital Library.

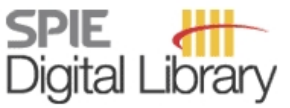

SPIEDigitalLibrary.org

Paper Numbering: Proceedings of SPIE follow an e-First publication model, with papers published first online and then in print and on CD-ROM. Papers are published as they are submitted and meet publication criteria. A unique, consistent, permanent citation identifier (CID) number is assigned to each article at the time of the first publication. Utilization of CIDs allows articles to be fully citable as soon as they are published online, and connects the same identifier to all online, print, and electronic versions of the publication. SPIE uses a six-digit CID article numbering system in which:

- The first four digits correspond to the SPIE volume number.

- The last two digits indicate publication order within the volume using a Base 36 numbering system employing both numerals and letters. These two-number sets start with 00, 01, 02, 03, 04, $05,06,07,08,09,0 A, 0 B \ldots 0 Z$, followed by 10-1Z, 20-2Z, etc.

The CID number appears on each page of the manuscript. The complete citation is used on the first page, and an abbreviated version on subsequent pages. Numbers in the index correspond to the last two digits of the six-digit CID number. 


\section{Contents}

ix Conference Committees
xiii Introduction

2012 INTERNATIONAL WORKSHOP ON IMAGE PROCESSING AND OPTICAL ENGINEERING

833502 Measurement of electro-optic effects in near-intrinsic silicon [8335-01]

J. Mu, J. Zhu, Z. Wang, Z. Chen, X. Liu, Y. Gao, G. Jia, Jilin Univ. (China)

833503 Study on the application of MRF and the D-S theory to image segmentation of the human brain and quantitative analysis of the brain tissue [8335-02]

Y. Guan, Y. Luo, T. Yang, L. Qiu, J. Li, Kunming Univ. of Science and Technology (China)

833504 A novel image encryption scheme based on the ergodicity of baker map [8335-03]

R. Ye, Y. Chen, Shantou Univ. (China)

833505 Intrinsic bistability effect of Yb-sensitized Tm upconversion emission in zirconium dioxide nanocrystal [8335-04]

D. X. Wang, M. Nie, Z. G. Zhang, H. Li, L. Li, X. L. Zhang, X. W. Zhang, R. M. Li, Harbin

Engineering Univ. (China)

833506 Strain measurement of weakening groove of separating unit based on 3D digital speckle correlation method [8335-05]

J. Zhou, H. Zhang, W. Guo, H. Wang, G. XU, W. Liu, Beijing Institute of Strength and

Environment Engineering (China)

833507 Application of skeletal age based on x-ray in selecting sports talents [8335-06]

Z. Mao, Wuhan Sports Univ. (China); G. XU, Jianghan Univ. (China); T. Song, Wuhan Sports Univ. (China)

833508 Research of power plant parameter based on the principal component analysis method [8335-07]

Y. Yang, Bohai Univ. (China); D. Zhang, Jinzhou Power Generation Co., Ltd. (China)

833509 Micro-structure characterization based on white light interferometry [8335-08]

T. Guo, Y. Zhang, S. Wang, L. Ma, X. Fu, X. Hu, Tianjin Univ. (China)

8335 OA Network tutoring strategy model based on multi-agent plan [8335-09]

J. Wang, Harbin Normal Univ. (China)

$8335 \mathrm{OB}$ A road sign detection and recognition system for mobile devices [8335-10]

B. Xiong, O. Izmirli, Connecticut College (United States) 
8335 OC SCOUT: a small vacuum chamber for nano-wire grid polarizer tests in the ultraviolet band [8335-11]

F. Landini, M. Pancrazzi, Univ. degli Studi di Firenze (Italy); M. Totaro, G. Pennelli, Univ. di Pisa (Italy); M. Romoli, Univ. degli Studi di Firenze (Italy)

8335 OD An applied study of human detection in single images [8335-12]

R. Liu, X. Xie, Swansea Univ. (United Kingdom)

$8335 \mathrm{OE} \quad$ Face recognition based tensor structure [8335-13]

D. Yang, Z. Ye, Y. Zhao, L. Liu, Yunnan Normal Univ. (China)

8335 OF High-performance illumination system design with new light source of LD array for laser projection display [8335-14]

H. Dong, Y. Zhang, H. Li, J. Duan, A. Shi, Q. Fang, Y. Liu, Institute of Semiconductors (China)

$83350 \mathrm{E}$ Enhancing of structures in coherence probe microscopy imaging [8335-15]

B. Heise, S. E. Schausberger, Johannes Kepler Univ. Linz (Austria); C. Maurer, M. Ritsch-Marte,

S. Bernet, Innsbruck Medical Univ. (Austria); D. Stifter, Johannes Kepler Univ. Linz (Austria)

$8335 \mathrm{OH} \quad$ Uncertain game-collaborative decision-making of combo-biding based on fuzzy Bernardo theory [8335-16]

R. Yao, Sichuan Univ. (China) and Huaneng Tibet Power Co., Ltd. (China); G. Ma, Sichuan Univ. (China)

8335 Ol Development of a NDVI detector based on optics and spectroscopy [8335-17]

W. Yang, M. Li, H. Sun, R. Zhao, China Agricultural Univ. (China)

$83350 \mathrm{~J} \quad$ Corn tassel detection based on image processing [8335-18]

W. Tang, Y. Zhang, D. Zhang, W. Yang, M. Li, China Agricultural Univ. (China)

8335 OK Feature selection combined category concentration degree with minimal set covering [8335-19]

H. Zhu, H. Li, Zhengzhou Univ. of Light Industry (China)

$8335 \mathrm{OL} \quad$ A study based on image processing for the bridge crack measurement [8335-20]

B. Xu, Chang'an Univ. (China) and Yancheng Institute of Technology (China); X. Zhou, X. Liu,

G. Yin, Chang'an Univ. (China)

8335 OM Target recognition research based on combined invariant moments [8335-21]

J. YU, J. Lv, X. Bai, Naval Aeronautical and Astronautical Univ. (China)

8335 ON Modified reduced-sum pyramid and one of its implementations [8335-22]

Y. Xie, J. Tang, Institute of Radar (China); L. Hao, Tsinghua Univ. (China)

833500 Fast and sensitive ultraviolet spectrum detection based on 32-anode photomultiplier tube array [8335-23]

L. Lu, Beijing Normal Univ. (China); B. Zhang, Beijing Key Lab. of Applied Optics (China);

J. Zhang, Beijing Normal Univ. (China) 
Application of binocular vision system to face detection and tracking in service robot [8335-24]

J. Qian, S. Ma, Y. Xu, X. Li, Y. Shen, Shanghai Univ. (China)

$83350 Q$ Fusion of panchromatic and multispectral remote sensing data using regression analysis in local region [8335-25]

Y. Liu, Q. Dai, L. Wang, Southwest Forestry Univ. (China)

8335 OR Error analysis of 3D laser scanning system for gangue monitoring [8335-26]

S. Hu, Y. Xia, BeiHang Univ. (China); A. Zhang, Capital Normal Univ. (China)

8335 OS Test of primary channel independence of LCD and Wavelength Piecewise LCD Color Model [8335-27]

H. Liu, Y. Liu, M. Huang, Y. Xu, B. Wu, Beijing Institute of Graphic Communication (China)

8335 OT Image processing method and implementation for a laser automatic tracking extensometer [8335-28]

Q. Tian, X. Du, Y. Liu, L. Yan, B. Chen, Zhejiang Univ. of Science and Technology (China)

8335 OU Robust image matching based on rotation and scale invariant shape context [8335-29]

J. Dou, J. Li, Shanghai Jiao Tong Univ. (China)

8335 OV Methods of scaling threshold color difference using printed samples [8335-30]

M. Huang, Beijing Institute of Graphic Communication (China); G. Cui, Univ. of Leeds

(United Kingdom); H. Liu, Beijing Institute of Graphic Communication (China); M. R. Luo, Univ. of Leeds (United Kingdom)

8335 OW Modification of color adaption on cross-media color matching [8335-31]

M. Huang, B. Wu, H. Liu, Y. Liu, Beijing Institute of Graphic Communication (China)

8335 OX Staircase effect alleviation based on multiscale analysis of Laplacian Pyramid [8335-32]

W. Chen, Y. Ye, Y. Huang, Univ. of Electronic Science and Technology of China (China)

8335 OY Super-resolution focusing of higher polarization order axially symmetric polarized beams [8335-33]

Z. Zhou, Beijing Information Science and Technology Univ. (China) and Tsinghua Univ.

(China); L. Zhu, Beijing Information Science and Technology Univ. (China)

$8335 \mathrm{OZ}$ Research on detection method of end gap of piston rings based on area array CCD and image processing [8335-34]

Y. Sun, Z. Wang, Q. Liu, L. Li, Tianjin Univ. (China)

833510 A phase retrieval algorithm for polychromatic x-ray in-line phase contrast imaging [8335-35]

X. Guo, X. Liu, M. Gu, C. Ni, B. Liu, S. Huang, Tongji Univ. (China)

833511 An efficient method to improve iris recognition performance based on multi-level fusion [8335-36]

F. Wang, China Univ. of Petroleum (China); X. Zhang, Xi'an Jiaotong Univ. (China) 
833512 Efficient suppression of the laser speckle in the laser projection system (Invited Paper) [8335-37]

Y. Zhang, H. Dong, H. Li, J. Duan, A. Shi, Q. Fang, Y. Liu, Institute of Semiconductors (China)

833513 Design of an integrated wide-angle broad polarization band pass filter [8335-38]

Z. Wang, J. Chu, F. Meng, Dalian Univ. of Technology (China) and Key Lab. for Micro/Nano Technology and System of Liao Ning Province (China)

833514 Power analysis of light source in laser projector [8335-39]

J. Duan, A. Shi, Y. Zhang, Q. Fang, Y. Liu, Institute of Semiconductor (China)

833515 Unequally protected packet transmission of SPIHT-compressed images [8335-40]

K.-T. Lay, C.-Y. Chou, National Taiwan Univ. of Science and Technology (Taiwan, China);

L.-J. Wang, National Taiwan Univ. of Science and Technology (Taiwan, China) and Tungnan Univ. (Taiwan, China)

833516 Study on non-rigid medical image registration based on optical flow model [8335-41] X. Lu, Y. Zhao, B. Zhang, H. Ma, Inner Mongolia Univ. of Science and Technology (China)

833517 Distribution characteristics analysis of sites around Taihu Lake basin based on DEM and ETM+ [8335-42]

L. Yu, Y. Nie, Institute of Remote Sensing Applications (China); Y. Zhang, Cybercity Sci-Tech Co., Ltd. (China)

833518 The study of chip orientation technology based on vision [8335-43]

Y. Xie, Z. He, Northeast Unv. at Qinhuangdao (China)

833519 Image classification by multi-instance learning with base sample selection [8335-44] Q. Pan, Zhuhai City Polytechnic College (China); G. Zhang, X.-Y. Zhang, Z.-M. Huang, GuangDong Univ. of Technology (China); J. Xiong, Ximalu Primary School (China)

8335 IA Categorizing video shots by utilizing SVM and wavelet [8335-45]

H. Jiang, X. Xia, Chongqing Univ. (China)

8335 1B Experimental investigation on the single-wavelength Brillouin fiber ring laser [8335-46] H. Gong, Y. Tu, Y. Jin, J. Wang, X. Dong, China Jiliang Univ. (China)

8335 IC A BDMI-VSK-T logic-based formal model in war simulation [8335-47]

B. Li, J. Tang, Naval Aeronautical and Astronautical Univ. (China)

8335 1D Comparison of modified burrows wheeler transform with JPEG and JPEG2000 for image compression [8335-48]

S. Shabani, A. Zolghadrasli, Shiraz Univ. (Iran, Islamic Republic of)

8335 IE Research on measurement of optical lens radius based on image processing [8335-49] W. Ma, X. Jin, H. Wang, Xi'an Univ. of Technology (China)

$8335 \mathrm{IF}$ Research on measurement of flying object nutation angle based on double linear CCD intersection [8335-50]

W. Ma, Q. Pang, J. Ni, Xi'an Technological Univ. (China) 
8335 1G A multiple object tracking method based on object chain [8335-51]

X. Luo, X. Ma, BeiHang Univ. (China)

$83351 \mathrm{H} \quad$ Learning based saliency weighted structural similarity [8335-52]

X. Sun, X. Liu, National Univ. of Defense Technology (China)

$833511 \quad$ Finite element analysis on mounting configurations for large-aperture optical element [8335-53]

R. F. SU, L. H. LU, Y. C. Liang, Y. Z. Cao, Harbin Institute of Technology (China)

$83351 \mathrm{~J} \quad$ Vision-guidance of micro- and nanorobots (Invited Paper) [8335-54]

T. Wortmann, C. Dahmen, S. Fatikow, Carl von Ossietzky Univ. Oldenburg (Germany)

$83351 \mathrm{~K} \quad$ Image registration based on geometric pattern matching [8335-55]

K. Wang, Y. Yan, T. Shi, S. Liu, Q. Xia, Huazhong Univ. of Science and Technology (China)

$83351 \mathrm{~L}$ Coastline extraction from tandem ERS 1/2 interferometric coherence map [8335-56]

Z. Wang, Chinese Academy of Surveying and Mapping (China), Shandong Univ. of Science and Technology (China), and State Bureau of Surveying and Mapping (China);

S. Yang, State Bureau of Surveying and Mapping (China); T. Chen, Shandong Univ. of Science and Technology (China)

$83351 \mathrm{M}$ Multiple contour sequences' segmentation and entity recognition methods in vision measurement [8335-57]

F. Yang, S. Liu, Harbin Institute of Technology (China)

$83351 \mathrm{~N} \quad$ Evaluated optical quality from wavefront aberration for some special human eyes [8335-58]

L. Fang, X. He, Nanchang Hangkong Univ. (China); Y. Wang, Tianjin Medical Univ. (China);

Y. Gong, Nanchang Hangkong Univ. (China)

833510 A modified algorithm for generation of 3D GVF field from point cloud [8335-59]

S. Liu, W. Niu, Harbin Institute of Technology (China)

8335 IP Image mosaicking of a section of a tunnel lining and the detection of cracks through the frequency histogram of connected elements concept [8335-60]

A. Mohanty, Indian Institute of Technology (India); T. T. Wang, National Taipei Univ. of Technology (Taiwan)

$83351 Q \quad$ Driver fatigue detection system based on DSP [8335-61]

Q. Wang, F. YU, L. Song, Harbin Univ. of Science and Technology (China)

8335 IR Manufacture of large-scale lightweight SiC mirror for space [8335-62]

Z. Huang, G. Liu, X. Liu, Z. Chen, D. Jiang, Shanghai Institute of Ceramics (China)

8335 is Experimental research on the electric field response characteristic of photorefractive spatial solitons in SBN:75 crystal [8335-63]

Y. Wang, Y. Jiang, G. Deng, X. Li, S. Zhang, B. Liang, Q. Guo, Hebei Univ. (China)

8335 1T Dynamical property analysis of fractionally damped van der pol oscillator and its application [8335-64]

Q. Zhong, C. Zhang, Northeast Forestry Univ. (China) 
$83351 \mathrm{U}$ Unsupervised hyperspectral imagery classification via sparse multi-way models and image fusion [8335-65]

Y. Zhao, J. Yang, Q. Zhang, L. Song, Northwestern Polytechnical Univ. (China)

$8335 \mathrm{lV}$ Variational approach to reconstruct surface from sparse and nonparallel contours in freehand 3D ultrasound imaging [8335-66]

S. Deng, L. Jiang, Y. Cao, J. Zhang, H. Zheng, Beijing Institute of Petrochemic Technology (China)

8335 IW Near-infrared microscopy imaging for quantitative analysis of active component in counterfeit imidacloprid [8335-67]

Y. Huang, China Agricultural Univ. (China); J. Cao, Tobacco Corp. of Dali (China); S. Ye,

J. Duan, L. Wu, Q. Li, S. Min, China Agricultural Univ. (China)

$83351 \mathrm{X}$ An improved interactive segmentation method for extracting the edge features of femur digital radiographs [8335-68]

S. Sun, Harbin Institute of Technology (China); B. Zhang, Harbin Institute of Technology

(China) and Harbin Univ. of Science and Technology (China); S. Meng, D. Liu, J. Sun, Harbin Institute of Technology (China)

$8335 \mathrm{IY}$ Texture structure analysis via description of primitive configuration and repeating pattern [8335-69]

Y. Zou, D. Dong, L. Wang, Tsinghua Univ. (China)

833512 Study on nonlinear filters in detection [8335-70]

H. Wang, F. Liu, Naval Univ. of Engineering (China); L. Hong, Navy Force (China); W. Liu,

Naval Univ. of Engineering (China)

833520 Research on feature extraction for chip resistors defect based on PCA [8335-71]

M. Q. Pan, Soochow Univ. (China), State Key Lab. of Fluid Power Transmission and Control (China), and State Key Laboratory of Transducer Technology (China); L. G. Chen, Soochow Univ. (China) and State Key Lab. of Fluid Power Transmission and Control (China); T. Chen, Soochow Univ. (China), State Key Lab. of Fluid Power Transmission and Control (China), and State Key Laboratory of Transducer Technology (China); M. X. Zhao, Harbin Institute of Technology (China); Z. H. Wang, Soochow Univ. (China)

$833521 \quad$ Image positioning accuracy analysis for the super low altitude remote sensing satellite [8335-72]

M. Xu, N. Zhou, Beihang Univ. (China)

833522 Research on identification and classification of texture based on MATLAB [8335-73]

G.-J. Suo, H. Guo, J-Y. Zhao, Z.-K. Zheng, J. Qian, Dalian Nationalities Univ. (China)

Author Index 


\title{
Conference Committees
}

\author{
Conference Chair
}

Dawei Meng, Harbin University of Science and Technology (China)

Committee Chairs

ShengHui Liu, Harbin University of Science and Technology (China)

Qun Ding, HeiLongJing University (China)

International and Scientific Committee

Binghai Zhou, Tongji University (China)

B. Žalik, University of Maribor (Slovenia)

Chung-Hung Tsai, Tzu Chi College of Technology (Taiwan, China)

Guisheng Yin, Harbin Engineering University (China)

G. Ganesan, Adikavi Nannaya University (India)

Hujie Huang, Harbin Institute of Technology (China)

Jinbao Li, HeiLongJing University (China)

Jianhua Wang, Harbin Normal University (China)

Mingyu Lu, Dalian Maritime University (China)

Ming-Hui Lee, Chinese Military Academy (Taiwan, China)

Qing He, North China Electric Power University (China)

Shaohua Xu, Northeast Forestry University (China)

Shifei Ding, China University of Mining and Technology (China)

Tianlong Gu, GuiLin University of Electronic Technology (China)

Yung-Cheng Hsieh, National Taiwan University of Arts (Taiwan, China)

Zhengtao Yu, Kunming University of Science and Technology (China)

Zongfu Xu, Harbin University (China)

Program Committee

Guodong Liu, Jiangnan University (China)

Hongguo Zhang, Harbin University of Science and Technology (China)

Hong Guo, Harbin University of Science and Technology (China)

Hua Zhang, Wuhan University of Science and Technology (China)

Jinbiao Zheng, East China University of Science and Technology

(China)

Jun Zhai, Dalian Maritime University (China)

Shuli Zhang, Harbin University of Science and Technology (China)

Wengang Che, Kunming University of Science and Technology (China)

Xiaoming Zhang, Beijing Institute of Petrochemical Technology (China)

Xiaoniu Li, Dalian Nationalities University (China)

Xuefeng Gao, Jilin University (China) 
Yu Gan, Harbin Institute of Technology (China)

Cui Linhai, Harbin University of Science and Technology (China)

Enming Zhao, Harbin Engineering University (China)

Hai Guo, Dalian Nationalities University (China)

Huamin Chen, Harbin University of Science and Technology (China)

Huijun Zhang, HeiLong Jing University (China)

Jun Wang, Harbin University of Science and Technology (China)

Liang Yin, Harbin Institute of Technology (China)

Mingyuan Ren, Harbin University of Science and Technology (China)

Peng Xu, Harbin University (China)

Shuli Zhang, Harbin University of Science and Technology (China)

Xiaofeng Zhao, HeiLongJing University (China)

Xuebin Lu, Harbin University of Science and Technology (China)

\section{Session Chairs}

1 Image/Video Coding and Transmission

Xuefeng Gao, Jilin University (China)

2 Image Scanning, Display, and Printing

Enming Zhao, Harbin Engineering University (China)

3 Image/Video Storage, Retrieval, and Authentication

Xiaoniu Li, Dalian Nationalities University (China)

$4 \quad$ Image Processing Applications

Mingyuan Ren, Harbin University of Science and Technology (China)

$5 \quad$ Signal Processing

Xuebin Lu, Harbin University of Science and Technology (China)

$6 \quad$ Pattern Recognition, Intelligent Computing

Hai Guo, Dalian Nationalities University (China)

7 Optical Design and Fabrication

Yu Gan, Harbin Institute of Technology (China)

$8 \quad$ Lasers and $X$-ray Optics

Peng Xu, Harbin University (China)

9 Astronomy, Optical Physics, and Chemistry

Cui Linhai, Harbin University of Science and Technology (China)

10 Integrated Optoelectronics

Hongguo Zhang, Harbin University of Science and Technology (China) 
11 Fiber Optics and Medical Optics

Huamin Chen, Harbin University of Science and Technology (China)

12 Electro-optical Systems

Xiaofeng Zhao, HeiLong Jing University (China)

Downloaded From: https://www.spiedigitallibrary.org/conference-proceedings-of-spie on 26 Apr 2023 Terms of Use: https://www.spiedigitallibrary.org/terms-of-use 
Downloaded From: https://www.spiedigitallibrary.org/conference-proceedings-of-spie on 26 Apr 2023 Terms of Use: https://www.spiedigitallibrary.org/terms-of-use

$-1$ 


\section{Introduction}

Following the great progress made in image processing and optical engineering, the 2012 International Workshop on Image Processing and Optical Engineering (IPOE 2012) aimed at providing a forum for presentation and discussion of stateof-the-art development in image/video coding and transmission; image scanning, display, and printing; image/video storage, retrieval, and authentication; image processing applications; signal processing; pattern recognition; intelligent computing; optical design and fabrication; lasers and $\mathrm{x}$ ray optics; astronomy, optical physics, and chemistry; integrated optoelectronics; fiber optics and medical optics; and electro-optical systems.

This conference, a workshop of 2012 International Conference on Information, Computing, and Telecommunications (ICICT2012), is co-sponsored by Harbin University of Science and Technology and the International Science and Engineering Research Center, and it is technically co-sponsored by Harbin Engineering University, Northeast Forestry University, Harbin Normal University, HeiLongJing University, Northeast Petroleum University, Harbin University, and Dalian Nationalities University. The purpose of IPOE 2012 is to bring together researchers and practitioners from academia, industry, and government to exchange their research ideas and results in the areas of the conference. In addition, the participants of the conference will have a chance to hear from renowned keynote speakers Professor Qing-Quan Li from Wuhan University China, and Professor Mahmoud Abdel-Aty from Sohag University, Egypt.

We would like to thank all the participants and the authors for their contributions. We would also like to gratefully acknowledge the SPIE staff, who enthusiastically supports the conference. In particular, we appreciate the full heart support of all the reviewers and staff members of the conference. We hope that IPOE 2012 will be successful and enjoyable to all participants and look forward to seeing all of you next year at the IPOE 2013. 
Downloaded From: https://www.spiedigitallibrary.org/conference-proceedings-of-spie on 26 Apr 2023 Terms of Use: https://www.spiedigitallibrary.org/terms-of-use

( 